\title{
Preparation and Characterization of Graphene Oxide / Cellulose Triacetate Forward Osmosis Membranes
}

\author{
Fang $\mathrm{LI}^{\mathrm{a}}$, Meilei $\mathrm{SUN}^{\mathrm{b}}$, Qianxun $\mathrm{CHENG}^{\mathrm{c}}$ and Bo YANG \\ ${ }^{1}$ College of environmental Science and Engineering, Donghua University, Shanghai \\ 201620, China \\ alifang@dhu.edu.cn', bunm11027@163.com, ${ }^{\mathrm{c}} 649450065 @$ qq.com, \\ dyangbo@dhu.edu.cn
}

\begin{abstract}
Forward osmosis (FO) is an emerging membrane separation technology in environmental and industrial process. This paper presents cellulose triacetate (CTA) membrane containing graphene oxide (GO) nanosheets via blending to enhance membrane performance in forward osmosis (FO) process. GO nanosheets with various loading were added into the casting solution to prepare the modified FO membranes. The prepared membranes were characterized by morphology analysis and permeability measurement. The result showed that the GO nanosheets effectively improved the performance of the CTA membranes. The CTA-0.2GO membrane had the highest water flux, reached 1.5 times as high as that of CTA membrane.
\end{abstract}

\section{Introduction}

With the development of economy and society, clean water production and regeneration have become the biggest global crises for clean water shortage. Recently, FO has received increasing attention in membrane industry. As FO is a membrane process driven by the osmosis pressure between draw solution (DS) and feed solution (FS) through a semi-permeable membrane [1]. In recent years, GO has received a closed attention in membrane research filed. Most researchers accept the model that the GO-chip distributes hydroxyl and epoxy groups at random. These hydrophilic function groups on GO provide the facility for investigators to modify the membrane surface [2-4].

In this work, the modified FO membranes were prepared by incorporating GO nanosheets in the CTA matrix. The GO nanosheets were expected to improve the structure and enhance the performance of CTA membranes.

* Corresponding author: ${ }^{\mathrm{a}}$ lifang@dhu.edu.cn 


\section{Experimental}

\subsection{Materials}

CTA(43-49 wt.\% acetyl)was provided by Celanese Co, LTD. (USA), 1,4-dioxane (dioxane, $\geqslant 99.5 \%)$, acetone $(\geq 99.5 \%)$, acetic acid $(100 \%)$ and sodium chloride $(\mathrm{NaCl}, 99.5 \%)$ were also purchased from Aladdin Co. LTD. All solvents were AR grade and were used directly without further purification.

\subsection{GO Preparation}

GO is prepared via improved Hummers method. We handled with natural graphite in pre-oxidization in first, and then produced via Hummers method [5].

\subsection{Membrane Fabrication}

CTA flat-sheet membranes were fabrication from polymer $14 \mathrm{wt} \%$ in the most examples of casting solution mixtures [6]. In this study, this composition of casting solutions used in this study is shown in the followings:

First, 1,4-dioxane and acetone mixed well at $85^{\circ} \mathrm{C}$, the CTA and $\mathrm{GO}$ added in the mixed solvent. Then acetic acid was mixed in the mixed solution. A thin layer of polymer solution was spread evenly on a smooth and hydrophilic glass plate using a $150 \mu \mathrm{m}$ casting knife and then immersed in the tap water coagulant bath at room temperature for phase separation to occur. Prior to each membrane casting, the glass plate was cleaned thoroughly in tap water, wiped dry and wiped with acetone using tissue, and dry before use. The as-cast membrane was gently peeled off from the glass plate and then soaked in a tap water bath at room temperature overnight to remove the residual solvent before testing. These CTA membranes were annealed in DI water at $75{ }^{\circ} \mathrm{C}$ for 2 min to improve their salt rejection properties.

TABLE 1 COMPOSITION AND CONCENTRATION OF CASTING SOLUTIONS FOR CTA FO MEMBRANES

\begin{tabular}{cccccc}
\hline & $\begin{array}{c}\text { CTA } \\
(\text { wt.\% })\end{array}$ & $\begin{array}{c}\text { Acetone } \\
(\text { wt.\% })\end{array}$ & $\begin{array}{c}\text { Acetic } \\
\text { acid(wt.\%) }\end{array}$ & $\begin{array}{c}\text { 1,4-dioxane } \\
(\text { wt.\% })\end{array}$ & $\begin{array}{c}\text { GO } \\
\text { (wt.\%) }\end{array}$ \\
\hline CTA & & & & 70 & 0 \\
CTA-0.05GO & \multirow{2}{*}{10} & \multirow{2}{*}{15} & 5 & 69.95 & 0.05 \\
CTA-0.1GO & & & & 69.9 & 0.1 \\
CTA-0.2GO & & & & 69.8 & 0.2 \\
\hline
\end{tabular}

\subsection{Evaluation of the Membrane Performance}

The performance of prepared novel membranes was characterized by measuring pure water flux. The method proposed by Cathy et al. was adopted to figure out the values of $\mathrm{J}_{\mathrm{w}}$ (water flux), $\mathrm{J}_{\mathrm{s}}$ (reverse salt flux), $A$ (water permeability), $B$ (salt permeability coefficient), $S$ (structure parameter) [7]. 


\section{Results and Discussion}

\subsection{Characterization of GO}

In order to confirm the GO nanosheets were obtained via the improved Hummers' method, the GO was characterized by FTIR and XRD analysis, as shown in Fig.1. The peaks at $3424 \mathrm{~cm}^{-1}$ and $1397 \mathrm{~cm}^{-1}$ of the $\mathrm{GO}$ nanosheets were assigned to $\mathrm{O}-\mathrm{H}$ stretching and $\mathrm{O}-\mathrm{H}$ deformation, respectively [8]. The $\mathrm{C}=\mathrm{O}$ stretching vibrations in the carboxyl group of GO was obviously visible around $1726 \mathrm{~cm}^{-1}$, whereas the peak at $1088 \mathrm{~cm}^{-1}$ was due to the C-C stretching of epoxy and alkoxy groups. The peak at $1630 \mathrm{~cm}^{-1}$ was assigned to the vibrations of the adsorbed water molecules and the contributions from the vibration of aromatic $\mathrm{C}=\mathrm{C}[9]$. As for the XRD pattern, the broad and relatively weak diffraction peak at $2 \theta=10.7^{\circ}(\mathrm{d}=0.826 \mathrm{~nm})$, which corresponds to the typical diffraction peak of GO nanosheets, is attributed to the (002) plane [10].
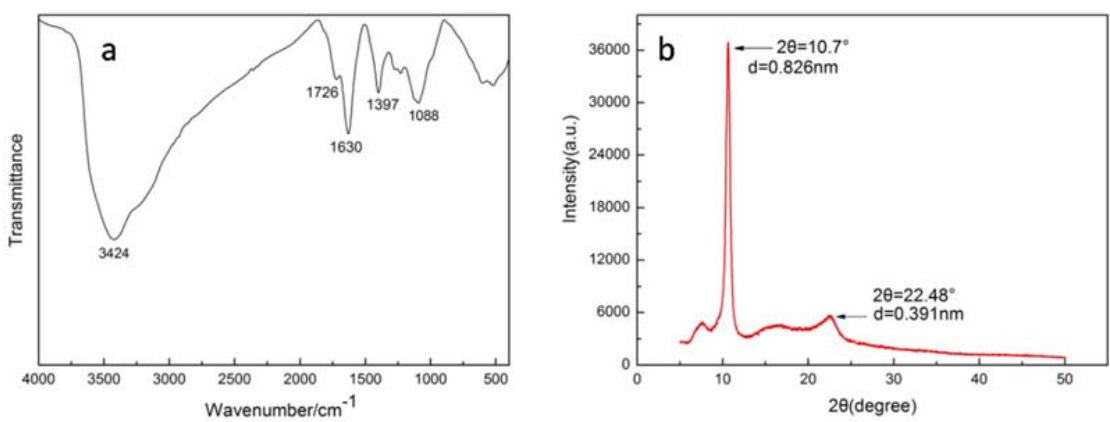

Fig.1 FTIR spectra and XRD pattern of GO nanosheets

\subsection{Characterization of GO-modified CTA Membranes}

As shown by the FI-IR spectra in Fig. 2, characteristic peaks were observed at 1720,1369 , and $1221 \mathrm{~cm}^{-1}$, which were associated with the stretching vibration of $\mathrm{C}=\mathrm{O}$, $\mathrm{C}-\mathrm{CH}_{3}, \mathrm{C}-\mathrm{O}-\mathrm{C}$, respectively. The spectrum of GO modified membrane appears weak peaks at 3430 and $2939 \mathrm{~cm}^{-1}$ associated with the stretching vibration of the $\mathrm{O}-\mathrm{H}$ and $\mathrm{C}-\mathrm{H}$ band which were more significant with higher GO loading. It was suggested that the hydrogen bonding interaction between the acetyl groups of CTA and the functional groups of the GO nanosheets might occurred during the membrane preparation.
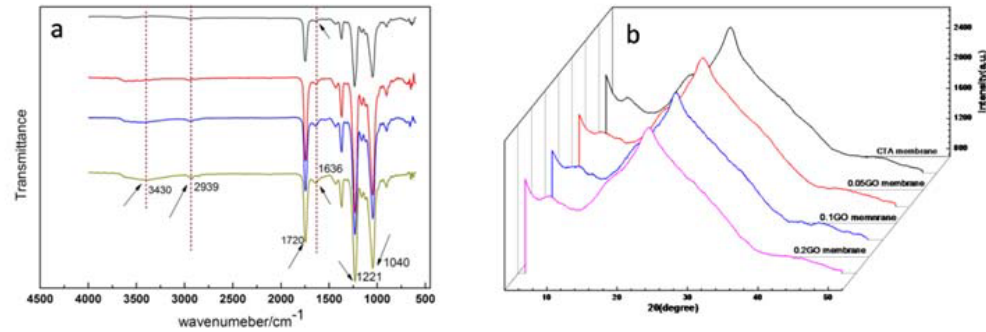

Fig. 2 FT-IR spectra and XRD pattern of CTA membranes 
As revealed in XRD pattern in Fig. 2, no GO specific peak was detected in the spectra characteristic for the composite materials which could suggest an efficient dispersion of GO nanosheets within the polymer matrix. Although a possible explanation for the lack of GO characteristic peak could be the very low amounts of GO incorporated in the polymer volume.

TABLE 2 TENSILE MODULUS AND TENSILE STRENGTH OF DIFFERENT MEMBRANES

\begin{tabular}{cccc}
\hline Membrane & $\begin{array}{c}\text { GO loading } \\
(\mathrm{wt} \%)\end{array}$ & $\begin{array}{c}\text { Tensile modules } \\
(\mathrm{MPa})\end{array}$ & $\begin{array}{c}\text { Tensile strength } \\
(\mathrm{MPa})\end{array}$ \\
\hline CTA & 0 & $104 \pm 6$ & $2.40 \pm 0.05$ \\
CTA-0.05GO & 0.05 & $110 \pm 5$ & $3.05 \pm 0.02$ \\
CTA-0.1GO & 0.1 & $122 \pm 8$ & $4.02 \pm 0.10$ \\
CTA-0.2GO & 0.2 & $128 \pm 10$ & $4.60 \pm 0.17$
\end{tabular}

As for Table 2, it was clear that GO embedding improved the tensile strength and elastic modulus which increased with the GO loading. The elastic modulus of CTA membrane increased from 104 to $128 \mathrm{MPa}$ as well as the tensile strength increased from 2.40 to 4.60MPa. It implied that the interaction between GO nanosheets and CTA matrix resulted in the mechanical improvement of CTA membranes.
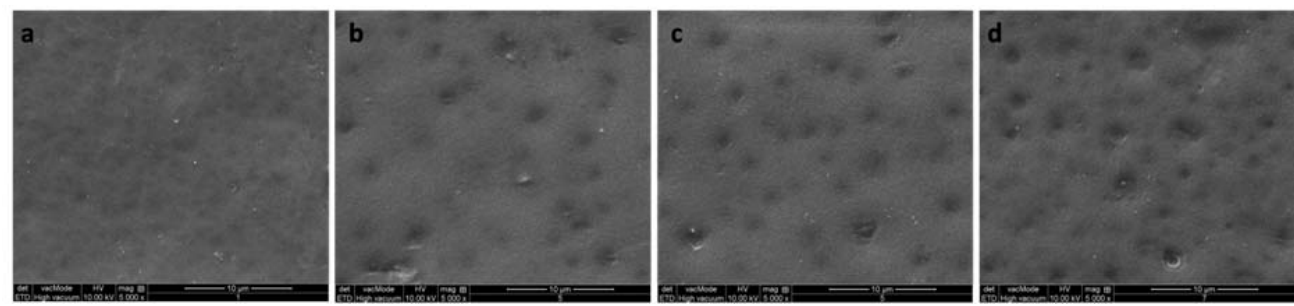

Fig. 3 a CTA membrane, b CTA-0.5GO membrane, c CTA-0.1GO membrane, d CTA-0.2 GO membrane.

Fig. 3 shows the FESEM images of the top surfaces of the pure and GO-modified CTA membranes. In general, the membrane prepared by phase inversion has dense top surface and porous bottom surface. From the FESEM images, it was clear that the number of dark point on the modified membrane surface increased with the GO loading. It was assumed that the dark points assigned to the agglomerated GO particles.

The roughness of the CTA membranes was characterized by AFM and the result was summarized in Table 3 . The roughness of the membrane declines sharply after the GO was embedded and decreased with the GO loading. Due to the affinity of GO towards water, the GO nanosheets moved towards top layer and enrich the nanoparticle concentration in the upper layer during the phase inversion.

TABLE 3 SURFACE ROUGHNESS OF MEMBRANE BY AFM

\begin{tabular}{llll}
\hline Membrane & $\mathrm{R}_{\mathrm{a}}(\mathrm{nm})$ & $\mathrm{R}_{\mathrm{q}}(\mathrm{nm})$ & $\mathrm{R}_{\mathrm{z}}(\mathrm{nm})$ \\
\hline CTA & $45.9 \pm 2.44$ & $55.6 \pm 0.013$ & $168.7 \pm 6.5$ \\
CTA-0.05GO & $15.9 \pm 10.7$ & $20.3 \pm 0.054$ & $60.5 \pm 10.5$ \\
CTA-0.1GO & $14.5 \pm 0.168$ & $18.9 \pm 2.68$ & $71.9 \pm 7.1$ \\
CTA-0.2GO & $9.42 \pm 13$ & $12.8 \pm 3.14$ & $108.9 \pm 10.9$ \\
\hline
\end{tabular}




\subsection{Effect of GO on CTA FO Membrane Performance}

Flux values of water and reverse salt are important index to evaluate the quality of FO membranes. The parameters of A and B represent water and salt permeability coefficient, respectively while $\mathrm{S}$ means structure coefficient. The water permeability and $\mathrm{NaCl}$ rejection shown in Table 4 were measured using a cross flow RO bench-scale setup. It can be found that the addition of GO in the CTA membranes remarkably improved the water permeability of the membrane. The water flux of pure CTA membrane was $1.26 \mathrm{~L} /\left(\mathrm{m}^{2} \cdot \mathrm{h} \cdot \mathrm{bar}\right)$ while CTA-0.05GO membrane exhibited a water flux of $1.41 \mathrm{~L} /\left(\mathrm{m}^{2} \cdot \mathrm{h} \cdot \mathrm{bar}\right)$. The value of A apparently increased with the $\mathrm{GO}$ loading. However, $\mathrm{NaCl}$ rejection of the modified membranes reduced as the pure CTA membrane had the highest rejection of $87.71 \%$ decline to $53.23 \%$ for CTA- 0.2 membrane. In addition, the B/A ratio decreased as the GO were added into the CTA matrix. CTA- $0.1 \mathrm{GO}$ membrane presented the lowest $\mathrm{B} / \mathrm{A}$ ratio of 174.17 among the modified FO membranes. The B/A ratio is an important selectivity parameter in FO applications which is directly related to the solute reverse transport. A lower B/A ratio is generally preferred for higher solute rejection, reduced fouling tendency, and more stable FO process operation $[11,12]$. It can be concluded that the selectivity of active layer was affected by the loading and property of the added GO. The change in the water and reverse salt permeability of modified membrane implied that defects in active layer may be induced by the GO clusters emerged on the substrate surface.

TABLE 4 VALUES OF $A, B$ AND $S$ OF FO MEMBRANES

\begin{tabular}{|c|c|c|c|c|c|c|c|}
\hline \multirow{2}{*}{ Membrane } & \multirow{2}{*}{$\begin{array}{l}\text { Contact } \\
\text { angle( }{ }^{\circ} \text { ) }\end{array}$} & \multicolumn{2}{|c|}{$A$} & \multirow{2}{*}{$\begin{array}{c}B \\
\left(10^{-8} \mathrm{~m} / \mathrm{s}\right)\end{array}$} & \multirow{2}{*}{$\begin{array}{c}B / A \\
(\mathrm{kPa})\end{array}$} & \multirow{2}{*}{$\begin{array}{c}\text { Rejection } \\
(\%)\end{array}$} & \multirow{2}{*}{$\begin{array}{c}S \\
(\mathrm{~mm})\end{array}$} \\
\hline & & $\mathrm{L} /\left(\mathrm{m}^{2}\right.$.h.bar $)$ & $\times 10^{-12} \mathrm{~m} / \mathrm{Pa} . \mathrm{s}$ & & & & \\
\hline CTA & 63.01 & 1.26 & 3.49 & 11.87 & 30.67 & 87.61 & 0.87 \\
\hline CTA-0.05 & 27.00 & 1.41 & 3.90 & 29.45 & 67.98 & 79.26 & 0.85 \\
\hline CTA- 0.1 & 26.36 & 1.74 & 4.83 & 93.45 & 174.17 & 59.30 & 0.57 \\
\hline CTA-0.2 & 20.56 & 3.67 & 10.19 & 182.72 & 60.47 & 53.23 & 0.67 \\
\hline
\end{tabular}

\section{Conclusions}

In this work, the modified CTA FO membranes were prepared by incorporating GO nanosheets in the CTA matrix. The prepared membranes were characterized by morphology analysis and performance measurement. The result revealed that the hydrogen bonding interactions between the acetyl groups of CTA and the functional groups of the GO nanosheets maybe occurred during the GO-modified CTA membrane preparation. Due to the affinity of GO nanosheets towards water, the nanosheets moved towards top layer and enrich the nanoparticle concentration on membrane surface during the phase inversion. Consequently, the permeability and selectivity of active layer was affected by the concentration of GO in CTA matrix. The change in the water and reverse salt permeability of modified membrane implied that defects in active layer which were possibly induced by the GO clusters emerged on the substrate surface.

\section{Acknowledgment}

This work is supported by the National Natural Science Foundation of China (Grant No. 51478099, 21477018), National Natural Science Foundation of Shanghai (Grant No. 13ZR1401000). 


\section{References}

1. T. Y. Cath, A. E. Childress and M. Elimelech. Forward osmosis: Principles, applications, and recent developments. J. Membr. Sci. 281 (2006). 70-87

2. X. Zhiwei. Organosilane-functionalized graphene oxide for enhanced antifouling and mechanical properties of polyvinylidene fluoride ultrafiltration membranes. J. Membr. Sci. 458 (2014). 1-13

3. B. M. Ganesh, A. M. Isloor and A. F. Ismail. Enhanced hydrophilicity and salt rejection study of graphene oxide-polysulfone mixed matrix membrane. Desalination 313 (2013). 199-207

4. Q. W. Shanshan W. Study on different reduction degree of graphene oxide waterborne polyurethane blend membranes performance study. Carbon technology(2013). 35-38+49

5. W. Guiling, L. Jincheng, T. Sheng, L. HuaiyuandC. Dianxue. Cobalt oxide-graphene nanocomposite as anode materials for lithium-ion batteries. J. Solid State Electrochem. 15 (2011). 2587-2592

6. R. C. OngandT.-S. Chung. Fabrication and positron annihilation spectroscopy (PAS) characterization of cellulose triacetate membranes for forward osmosis. J. Membr. Sci. 394-395 (2012). 230-240

7. C. Klaysom, T. Y. Cath, T. DepuydtandI. F. J. Vankelecom. Forward and pressure retarded osmosis: potential solutions for global challenges in energy and water supply. Chem. Soc. Rev. 42 (2013). 6959-6989

8. Y. Liang. Preparation and characterization of HPEI-GO/PES ultrafiltration membrane with antifouling and antibacterial properties. J. Membr. Sci. 447 (2013). 452-462

9. D. W. Boukhvalov, M. I. KatsnelsonandY.-W. Son. Origin of Anomalous Water Permeation through Graphene Oxide Membrane. Nano Letters 13 (2013). 3930-3935

10. S. Xia, M. Ni, T. Zhu, Y. ZhaoandN. Li. Ultrathin graphene oxide nanosheet membranes with various d-spacing assembled using the pressure-assisted filtration method for removing natural organic matter. Desalination 371 (2015). 78-87

11. W. C. L. Lay. Analysis of Salt Accumulation in a Forward Osmosis System. Sep. Sci. Technol 47 (2012). 1837-1848

12. W. Gao. Membrane fouling control in ultrafiltration technology for drinking water production: A review. Desalination 272 (2011). 1-8 